ISBN 978-93-84422-76-9

5th International Conference on Food, Agricultural, Biological and Medical Science

(FABMS-2017)

Bangkok (Thailand) Feb. 6-7, 2017

\title{
Potential of Trichoderma species as biocontrol agent against Curvularia lunata causing fruit rot of tomato (Lycopersicum esculentum Mill.)
}

\author{
Sehrish Iftikhar ${ }^{1}$, Ahmad Ali Shahid ${ }^{1}$, Kiran Nawaz ${ }^{1}$, and Waheed Anwar ${ }^{1}$ \\ ${ }^{1}$ Institute of Agricultural Sciences, University of the Punjab, Lahore, Pakistan
}

\begin{abstract}
Tomato (Lycopersicum esculentum Mill.) is one of the important economic vegetable crops which is attacked by several serious diseases. In this study, Curvularia lunata was isolated from tomato fruit and characterized by using morphological and molecular techniques. This is the first report of C. lunata from tomato causing fruit rot in Pakistan. Twenty five isolates of Trichoderma were isolated from different healthy crops and ornamental plants and identified using morphological characteristics. Twenty five Trichoderma isolates were screened for their biocontrol activity against Curvularia lunata. Twelve of these isolates (Isolate T1 to T12) exhibited significant biocontrol potential and were further studied. Initial counter inhibition was detected in all the twelve dual culture assays where Trichoderma posed variable degree of inhibition on C. lunata. All Trichoderma isolates had considerable antagonistic effect on mycelial growth of the C. lunata in dual cultures compared to the control. Parasitic interaction of Trichoderma on Curvularia was observed in all the assays. Among the twelve isolates of Trichoderma, T. viride (Isolate T1) was found to show best activity followed by two isolates of T. harzianum and T. hamatum in terms of time taken to parasitize Curvularia. In present study Curvularia was reported for the first from Pakistan to cause fruit rot of tomato and stresses on its quick control using Trichoderma as biocontrol agent. Since all Trichoderma isolates evaluated were effective in controlling colony growth of $C$. lunata, they could be tried as a broad spectrum biological control agent in the green house and under field conditions.
\end{abstract}

Keywords: Antagonist, Biocontrol, Trichoderma, Fruit rot.

\section{Introduction}

Tomato (Lycopersicon esculentum Mill.) is one of the most extensively consumed crops because of its flavorsome fruit, savor and nutritious values. Tomato is beneficial to human health as it reduces the risk of cardiovascular diseases and cancers due to the presence of high contents of vitamin $\mathrm{A}$ and $\mathrm{C}$, powerful antioxidant components, low calories, betacarotene and potassium [1]. Low production cost and short-duration appeal tomato growers for cultivation of tomato and gain high yields throughout the year predominantly under warmer climatic conditions [2]. Diversified environmental conditions of Pakistan favor the production of highquality tomatoes around the year. Five thousand seventy-four hundred tons tomato is produced annually in Pakistan [3]. Major impediments in the production of crops are the diseases which can reduce the yield up to $100 \%$. Various plant pathogens attack tomato plant including viruses, bacteria, fungi, and nematodes [4] as they can attack tomato at all stages of growth and disseminate through air, soil, water, seed and vector. Fruit rot of tomato is caused a by a number of fungi one of them is Curvularia lunata. It is reported for the first time causing fruit rot of tomato in Pakistan. There are previous reports of $C$. lunata on many other crops which suggest that this pathogen has the potential to infect the host plants with wide range of species.

Trichoderma is an antagonistic mycoparasite which has the ability to control newly entering along with already established infection. Many pathogens including Rhizoctonia, Curvularia, Botrytis, Pythium, and Sclerotinia has been controlled using Trichoderma in many crops like grapes, apples, lettuce, onion, and others 
[6]. Trichoderma applies different mechanisms to suppress the pathogen growth. Trichoderma controls the pathogen by competing for nutrients, causing myco-parasitism and antibiosis [7] and can detect the presence of fungi, then grow towards them and parasitize them resulting in direct biocontrol. Many volatile and non-volatile toxic metabolites are excreted by Trichoderma strains which can hinder the growth of pathogenic fungi. Trichoderma can grow on a variety of carbon and nitrogen source, which makes it easy to use for formulation and delivery system. Synthetic pesticides that combat phytopathogenic organisms are responsible for stabilization and increase in crop production. However, pesticide-tolerant pathogens have been development due to increase in the use of pesticides [8] and pesticide residues have been accumulated in the food chain above safe limits [9]. Use of biological control agents to combat plant disease is considered as environmental friendly method as compared to chemical control. The objectives of this study are i). Sampling of diseased tomato fruits, ii). Isolation and identification of pathogenic fungi ( $C$. lunata) iii). Isolation and identification of biocontrol agent (Trichoderma) iv). Biological control of $C$. lunata using Trichoderma.

\section{Material and Methods}

\subsection{Sampling}

Tomato fruits showing the symptoms of rot were observed in April 2015, during a survey of tunnels where tomato plants (cv. Roma) were growing at the University of the Punjab, Lahore, Pakistan. Disease incidence on affected fruits was $70 \%$. The symptoms observed on the tomato fruit included water-soaked lesions of $1-2 \mathrm{~cm}$ which enlarged gradually $(3$ to $4 \mathrm{~cm}$ ). Tomato fruits showing the symptoms of fruit rot were collected for isolation of pathogen (Fig. 1).

\subsection{Isolation of pathogenic fungi}

Diseased fruit tissues $(3 \mathrm{~mm} \times 3 \mathrm{~mm})$ were cut from lesion edges, surface sterilized with sodium hypochlorite (1\%), for $3 \mathrm{~min}$, and washed with sterile distilled water. The infected tissues were inoculated on potato dextrose agar (PDA) and incubated at $27^{\circ} \mathrm{C}$ for

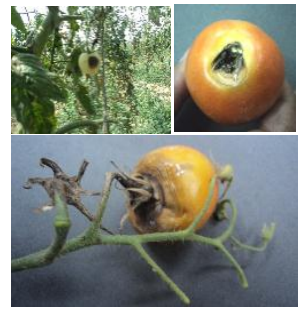

Fig. 1: Fruit rot symptoms on tomato fruit 5 days. The culture was purified by single spore technique.

\subsection{Morphological identification}

The pathogen was identified on the basis of morphological characteristics on culture media in the laboratory (in-vitro). The main characteristics considered were colony color, margins, shape, and pigmentation, mycelium septation, color, branching and conidia size, color, shape, and septation.

\subsection{Molecular identification}

DNA extraction was done by CTAB method [10]. ITS1 and ITS4 primers were used to amplify internal transcribed spacer region of extracted DNA [11]. The PCR product was purified and sequenced.

\subsection{Pathogenicity test}

Pathogenicity tests were conducted on healthy tomato (cv. Roma) fruit using the technique described by [12] Okigbo. Fruits were surface sterilized and a disc of 5-mm was removed from the fruit with a cork borer and replaced with a disc of agar colonized by $C$. lunata. Control fruits were inoculated with a disc of PDA. Three tomatoes each with two inoculation points were wrapped in a plastic bag and stored at $27^{\circ} \mathrm{C}$ (16h light). Tomatoes were observed after 5 days for the development of pathogen related symptoms.

\subsection{Isolation of biocontrol agents}

Numerous ornamental plants and healthy crop from Lahore, Pakistan were surveyed to isolate biocontrol agents, Trichoderma spp.

\subsubsection{Isolation of Trichoderma from rhizosphere [13] [14]}

Roots were excised from the plants and washed with sterilized distilled water. The water from the washing was considered as a sample which contains microbes from the rhizosphere and $0.1 \mathrm{~mL}$ of this suspension was spread on medium. 


\subsubsection{Isolation of Trichoderma from rhizoplane [13] [14]}

All the soil particles were removed by washing the roots with tap water and cut into 3-4 cm pieces. The pieces were washed several times with sterilized water and left in it for 5 minutes. Subsequently, the pieces were inoculated on medium (PDA).

\subsubsection{Isolation of endophytic Trichoderma [15]}

All the soil particles were removed by washing the roots with tap water and cut into 3-4 $\mathrm{cm}$ pieces. The pieces were sterilized with $1 \%$ of $\mathrm{NaOCl}$ for 30 seconds. The pieces were washed with distilled water. About $5 \mathrm{~mm}$ section was cut off from root and placed on PDA.

\subsection{Morphological identification}

The green fungus was identified at genus level using the method of [16] Domsch et al. Species level identification was done using the taxonomic key of [17] Samuels et al.

\subsection{Test of antagonism by dual culture technique}

Twenty five Trichoderma isolates were isolated and used to evaluate their biocontrol potential against Curvularia lunata by dual culture technique on PDA medium [18]. The mycelial plugs (5 mm diameter) of $C$. lunata and Trichoderma antagonists were placed on the same dish $3 \mathrm{~cm}$ apart from each other on PDA plates. Each plate received two disks, one with Trichoderma mycelium and another with Curvularia mycelium. Twelve isolates of Trichoderma displaying significant antagonistic potential against pathogen were (T1 to T12) inspected for their biocontrol potential. The remaining thirteen isolates were not investigated further as they were slow growing or exhibited weak antagonism.

\subsection{Observations recorded in Trichoderma-Curvularia dual culture}

The colony interactions were measured as percentage of inhibition of radial growth of $C$. lunata by the following formula: Percentage of inhibition $=\mathrm{R} 1-\mathrm{R} 2 / \mathrm{R} 2 \times 100$

(R1 - Radial growth of the pathogen towards opposite side in control plate, R2 - Radial growth of the pathogen towards the opponent antagonist in test plate)

\section{Results and discussion}

\subsection{Morphological identification of pathogen}

Curvularia lunata grew fast on PDA with cottony brown appearance. Conidiophores were brown, multiseptate, straight to flexuous, mostly simple but sometimes branched. Conidia were fusiform, 3 to 5 celled, clavate, 26 to $28 \mu \mathrm{m}$ long, 8 to $10 \mu \mathrm{m}$ wide. The third cell of conidia was slightly curved and was larger than the others (Fig. 2). The pathogen was identified as Curvularia lunata (Wakk.) Boedijin on the basis of colony and morphological characters [19].

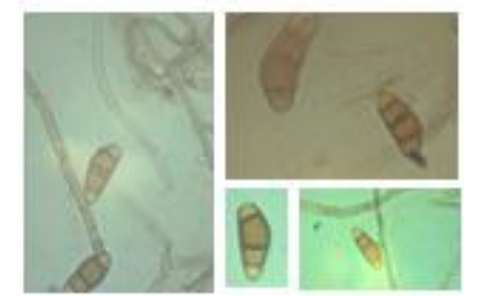

Fig. 2: Conidia of C. lunata at $100 \mathrm{X}$

\subsection{Molecular identification}

The sequence was subjected to BLAST analyses to compare with those in GenBank. The 525 bp sequence has $100 \%$ similarity with sequences of $C$. lunata in GenBank. The sequence was submitted to GenBank (Accession No. LN879926). 


\subsection{Pathogenicity test}

After five days post inoculation, fruit rot symptoms of brown colored water soaked lesions appeared on all the inoculated fruits. The pathogen was re-isolated from the diseased fruits and identified as $C$. lunata. Control fruits inoculated with PDA discs displayed no fruit rot symptoms.

\subsection{Efficacy of Trichoderma spp. to control Curvularia on dual culture plates}

Results from dual culture assay depicted that all the Trichoderma isolates inhibited the mycelial growth of the pathogen. Curvularia lunata as a single culture was actively growing and covered the $9 \mathrm{~mm}$ entire agar surface within five days. Dual culture assays showed that $T$. viride (isolate T1) was most efficient isolate in reducing the mycelial growth of the pathogen with percentage inhibition of $93.8 \%$. All the tested isolates of biocontrol agent inhibited the growth of the pathogenic fungi by more than $80 \%$. T. hamatum and T. harzianum (isolates T4 and T6) were superior to others in inhibiting the mycelial growth of the pathogen. T. atroviride (isolate T9 and T10) showed percentage inhibition of $83.6 \%$ and $80 \%$. Various Trichoderma spp. are rapidly growing, produce potent antibiotics and strong opportunistic fungi [20]. The parasitic T. viride, T. hamatum, and $T$. harzianum covered the host colony and resulted in complete degradation of the pathogen. All isolates of $T$. hamatum inhibited the growth of $C$. lunata with isolate T4 showing pronounced antifungal activity with percentage inhibition (92.2\%) while T3 the lowest (86.2\%). T. longibrachiatum (isolate T11 and T12) resulted in $84.6 \%$ and $85.2 \%$ reduction in Curvularia growth (Table 1).

TABLE I: Measurements on Trichoderma-Curvularia interaction

\begin{tabular}{|c|c|c|c|c|c|}
\hline Source & Species & Isolate no. & $\mathrm{R} 1(\mathrm{~mm})$ & $\mathrm{R} 2(\mathrm{~mm})$ & Percentage of inhibition (\%) \\
\hline Rose (Rosa sp.) & T. viride & T1 & \multirow{12}{*}{50} & 3.1 & $93.8 \pm 1.2$ \\
\hline Rose (Rosa sp.) & T. viride & $\mathrm{T} 2$ & & 7.4 & $85.2 \pm 1.5$ \\
\hline Pepal (Ficus religiosa) & T. hamatum & T3 & & 6.9 & $86.2 \pm 0.9$ \\
\hline Rose (Rosa sp.) & T. hamatum & $\mathrm{T} 4$ & & 3.9 & $92.2 \pm 2.1$ \\
\hline Aleo vera (Aleo vera) & T. hamatum & T5 & & 5.9 & $88.2 \pm 1.2$ \\
\hline Mango (Mangifera indica) & T. harzianum & T6 & & 4.9 & $90.2 \pm 0.7$ \\
\hline Rose (Rosa sp.) & T. harzianum & $\mathrm{T} 7$ & & 6.2 & $87.6 \pm 2.4$ \\
\hline Aleo vera (Aleo vera) & T. harzianum & $\mathrm{T} 8$ & & 7.1 & $85.8 \pm 1.4$ \\
\hline Bougainvillae "Buttiana & T. atroviride & T9 & & 8.2 & $83.6 \pm 1.7$ \\
\hline Rose (Rosa sp.) & T. atroviride & $\mathrm{T} 10$ & & 10 & $80.0 \pm 2.4$ \\
\hline Rose (Rosa sp.) & T. longibrachiatum & $\mathrm{T} 11$ & & 7.7 & $84.6 \pm 1.1$ \\
\hline Aleo vera (Aleo vera) & T. longibrachiatum & $\mathrm{T} 12$ & & 7.4 & $85.2 \pm 1.3$ \\
\hline
\end{tabular}

The growth of all the $T$. viride isolates was considerably faster than the pathogen on PDA under same conditions as pathogenic culture. The isolates also sporulated on the pathogen colony (Fig. 3). All the isolates of $T$. atroviride and T. longibrachiatum showed relatively less inhibition as compared to other Trichoderma isolates. T. atroviride (T9) showed inhibition of $79.97 \%$ in radial growth of $C$. lunata and over grew on the colony of the pathogen. Since 1930, Trichoderma species are known to possess antifungal potential and efforts have been made for their use in controlling the plant diseases [21]. Trichoderma sporulated heavily at the border of the zone of inhibition marked by the influence of Curvularia. In an advanced phase the interface, Trichoderma spp. overwhelm Curvularia and some isolates of Trichoderma covered the area on which Curvularia was growing, yet, T. atroviride (T10) and T. longibrachiatum (T11) displayed a robust counter inhibition to the growth of Curvularia and showed that peripheral area around Curvularia unoccupied.
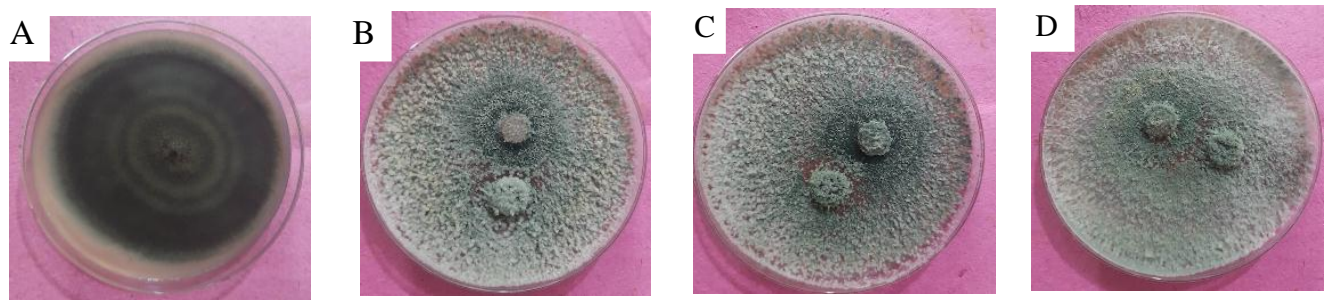

Fig 3: Biocontrol of Trichoderma against C. lunata A). T. viride B). T. hamatum C). T. Harzianum D). Control 


\subsection{Time}

Figure 4 shows the time taken by each Trichoderma isolates to overcome Curvularia. Trichoderma viride (isolate T1) and two isolates of T. hamatum (isolate T4 and T5) took the least time to cross the inhibition zone and parasitizing Curvularia lunata. Fast rate of growth and aggressive mechanisms are considered as critical characters of biocontrol agent in the management of disease control on the agricultural field. Trichoderma must overcome the pathogen before the pathogen thrives and cause disease in plants. Therefore, measuring the time taken by biocontrol agent to overwhelm the pathogen is an important factor while screening for potential Trichoderma spp. Trichoderma spp. were fast growing and spread rapidly on the culture media. They encircled the Curvularia and even the distal side of Curvularia was covered by the Trichoderma. All the isolates of Trichoderma trapped Curvularia from all sides except $T$. atroviride (T10) and T. longibrachiatum (T11). Trichoderma isolate T1, T4, and T5, showed considerable activity against Curvularia and took minimum time to overcome C. lunata. T. longibrachiatum (T11) invaded Curvularia colony on agar culture media after 96 hours (Fig. 4).

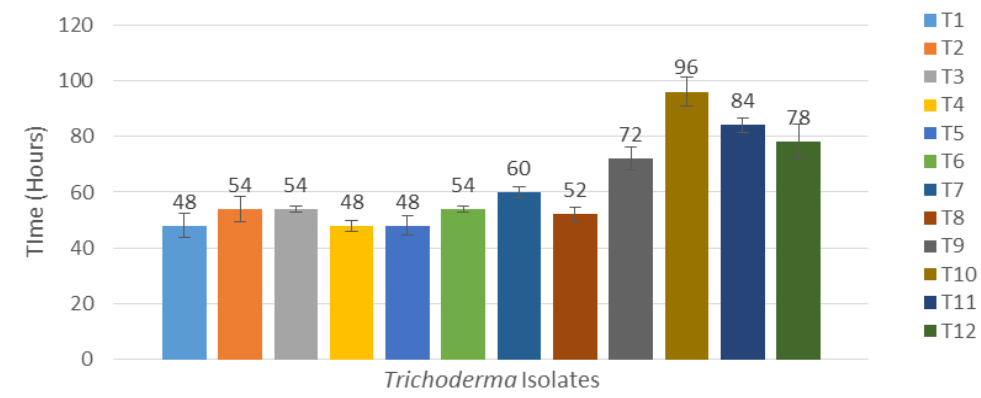

Fig. 4: Comparison of time taken by Trichoderma species to overwhelm C. lunata

Many researchers have isolated numerous antibiotics from Trichoderma spp. Antibiotic viridin produced by T. viride is reported to inhibit the germination of spores in many fungi. Modification in membrane permeability of liposomes and disturbance in ionic balance caused by trichorzianines is reported [22]. Beta-glucan synthase activity was inhibited in pathogenic fungi by Trichoderma spp. as reported by some researchers [23] which prevents the rebuilding of the host cell wall. Chitinolytic enzymes of $T$. atroviride inhibit germination and elongation of hyphae in many pathogenic fungi. Some cellulolytic enzymes have been isolated from $T$. longibrachiatum which has been implicated in biocontrol activity [24]. Trichoderma spp. can hyper-parasitize the pathogenic fungi and are considered highly efficient antagonist $[25,26]$.

\section{Conclusion}

Finally, the development of new antimicrobial products is vital in controlling the threats posed by some pathogens. It can be fairly concluded that Trichoderma spp. have a great potential as sources for novel lead products to combat plant pathogens with specific antifungal properties. The observations indicate that Trichoderma viride, T. hamatum, and T. harzianum were most effective, with pronounced antifungal activity and took the least time to parasitize the $C$. lunata. We think that more efforts are needed to integrate the efficient Trichoderma spp. with each other to become more effective toward the plant pathogenic microbes.

\section{References}

[1] F. Shidfar, N. Froghifar, M. Vafa, A. Rajab, S. Hosseini, S. Shidfar, and M. Gohari, "The effects of tomato consumption on serum glucose, apolipoprotein B, apolipoprotein AI, homocysteine and blood pressure in type 2 diabetic patients," International journal of food sciences and nutrition, vol. 62(3), pp 289-294, 2011.

https://doi.org/10.3109/09637486.2010.529072 
[2] S. Naika, J. V. L. de Jeude, M. de Goffau, M. Hilmi and B.van Dam, “Cultivation of tomato," $.4^{\text {th }}$ ed. Digigrafi publishing, Wageningen, Netherlands: Agromisa, 2005, ISBN Agromisa: 90-8573-039-2.

[3] GOP. Agricultural Statistics of Pakistan. Statistics Division, 2012-13, Govt. Pakistan, Islamabad.

[4] G. N. Agrios, Plant Pathology. 5th ed. Acadamic Press, NY, US, 2005, pp. 922.

[5] J. K. Stone, C. W. Bacon, and J. F. White, "An Overview of Endophytic Microbes: Endophytism Defined." Microbial endophytes, vol. 3, pp. 29-33, 2000.

[6] T. Benítez, A. M. Rincón, M. C. Limón, and A. C. Codón, "Biocontrol mechanisms of Thrichoderma strains." International microbiology, vol. 7(40), pp. 249-260, 2010.

[7] I, Chet, "Trichoderma-application, mode of action and potential as a biocontrol agent of soil borne plant pathogenic fungi,” Chet I (ed.), Innovative approaches to plant disease control, Wiley, New York, pp. 137-160, 1987.

[8] T. Staub, "Fungicide Resistance: Practical Experience with Antiresistance Strategies and the Role of Integrated Use." Annual review of phytopathology, vol. 29(1), pp. 421-42, 1991.

https://doi.org/10.1146/annurev.py.29.090191.002225

[9] Y. El-Nahhal, "Contamination and safety status of plant food in Arab countries," J. Appl. Sci, vol. 4, pp. 411-417, 2004. https://doi.org/10.3923/jas.2004.411.417

[10] J. J. Doyle, and J. L. Doyle, "A rapid DNA isolation procedure from small quantities of fresh leaf tissues," Phytochem Bull, vol. 19, pp. 11. 1987.

[11] T.J. White, T. Bruns, and S. Lee, "Amplification and direct sequencing of fungal ribosomal RNA genes for phylogenetics,” Taylor J., Innis A., Gelfand D.H., Sninsky J.J. (eds). PCR Protocols, Academic Press, San Diego, CA, USA, pp. 315-322, 1990.

https://doi.org/10.1016/b978-0-12-372180-8.50042-1

[12] R. N. Okigbo, "Variation in phytochemical properties of selected fungicidal aqueous extract of some plant leaves in Kogi State, Nigeria,” American European Journal of Sustainable Agriculture, vol. 3 (3), pp. 407-409, 2009.

[13] H. A. H. Hasan, "Gibberellin and auxin production by plant root-fungi and their biosynthesis under salinity-calcium interaction," Rostlinna vyroba, vol. 48(3), pp. 101-106, 2002.

[14] A. Pandey, and L.M.S. Palni, "Isolation of Pseudomonas corrugata from Sikkim Himalaya," World Journal of Microbiology and Biotechnology, vol. 14(3), pp. 411-413, 1998.

https://doi.org/10.1023/A:1008825514148

[15] N. C. Paul, W. K. Kin, S. K. Woo, M. S. Park, and S. H. Yu, "Fungal endophytes in roots of Aralia species and their antifungal activity," Plant Pathol. J., vol. 23(4), pp. 287-294, 2007.

https://doi.org/10.5423/PPJ.2007.23.4.287

[16] K. H. Domsch, W. Gams, T. H. Anderson, Compendium of soil fungi Academic Press London 809, 1980.

[17] G. J. Samuels, P. Chaverri, D. F. Farr, and E. B. McCray, USDA, Beltsville, USA. Trichoderma online systematic $\begin{array}{lllll}\text { Botany and } & \text { Laboratory }\end{array}$ http://nt.arsgrin.gov/taxadescriptions/keys/TrichodermaIndex.cfm.

[18] N. J. Fokemma, "The role of saprophytic fungi in antagonism against Derchslera sorokaniana (Helminthosporium sativum) on agar plates and on rye leaves with pollen," Physiol. Plant Pathol., vol. 3, pp. 195-205, 1973.

https://doi.org/10.1016/0048-4059(73)90082-9

[19] M. B. Ellis, "Dematiaceous Hyphomycetes,” CMI, Kew, Surrey, UK, 1971.

[20] S. L. Woo, F. Scala, M. Ruocco, and M. Lorito, "The molecular biology of the interactions between Trichoderma spp., phytopathogenic fungi and plants," Phytopathology, vol. 96, pp. 181-185, 2006.

https://doi.org/10.1094/PHYTO-96-0181 
[21] L. G. Hjeljord, and A. Tronsmo, "Trichoderma and Gliocladium in biocontrol: an overwiew," in Kubicek, C.P. \& Harman, G.E. (ed), Trichoderma and Gliocladium. Taylor \& Francis, Ltd., London. United Kingdom, pp.135-151, 1998.

[22] C. Goulard, S. Hlimi, S. Rebuffat, and B. Bodo, "Trichorzins HA and MA, antibiotic peptides from Trichoderma harzianum. I: Fermentation, isolation and biological properties" J. Antibiot, vol. 48, pp. 1248-1253, 1995.

https://doi.org/10.7164/antibiotics.48.1248

[23] V. Fogliano, A. Ballio, M. Gallo, S. L. Woo, F. Scala, M. Lorito, "Pseudomonas lipodepsipeptides and fungal cell wall-degrading enzymes act synergistically in biological control," Mol. Plant-Microbe Interact, vol. 15, pp. 323-333, 2002.

https://doi.org/10.1094/MPMI.2002.15.4.323

[24] Q. Migheli, O. Friard, D. Ramon-Vidal, L. Gonzalez-Candelas, "Hypercellulolytic transformants of Trichoderma longibrachiatum are active in reducing Pythium damping-off on cucumber," In Daniels MJ (ed.), Advances in molecular genetics of plant-microbe interactions, Kluwer, Dordrecht, vol. 3, pp. 395-398, 1994.

https://doi.org/10.1007/978-94-011-0177-6_59

[25] H. L. Barnett, and F. L. Binder, “The fungal host-parasite relationship,” Annu. Rev. Phytopathol, vol. 11, pp. 273-292, 1973.

https://doi.org/10.1146/annurev.py.11.090173.001421

[26] L. W. DURRELL, "Hyphal invasion by Trichoderma viride,” Mycopathol. et Mycol. Appl, vol. 35, pp. 138-144, 1968. https://doi.org/10.1007/BF02049577 